\title{
Gel Electrophoresis Analysis of the Hard Coronas of Human Serum Albumin on Silica Nanoparticles: Size Dependence of Corona Formation
}

\author{
Sung-Jong Kim ${ }^{\mathrm{a}}$ and Sang Yun Han ${ }^{\dagger, *}$ \\ Center for Nano-Bio Convergence, Korea Research Institute of Standards and Science, Daejeon 305-340, Korea \\ 'Department of Nanochemistry, Gachon University, Gyeonggi 461-701, Korea. ${ }^{*}$ E-mail: sanghan@gachon.ac.kr \\ Received April 1, 2014, Accepted May 2, 2014
}

\begin{abstract}
The rapid and spontaneous adsorption of proteins on nanoparticle (NP) surfaces in biological fluids such as blood is an important phenomenon as it possibly determines "what the cells see" and, thus, the fates of NPs in living organisms. In order to quantitatively understand protein coronas at the molecular level, we investigated human serum albumin (HSA) coronas that were produced on silica NPs of $20 \mathrm{~nm}$ and $50 \mathrm{~nm}$ diameters using conventional gel electrophoresis. Analysis of the concentration dependence of protein adsorption showed that HSA coronas preferentially formed a monolayer on silica NPs and revealed the presence of hard protein coronas. HSA adsorption was clearly dependent on NP size, and this might be due to the different surface curvatures of NPs of different sizes.
\end{abstract}

Key Words : Protein coronas, Silica nanoparticles, Size dependence, Gel electrophoresis, Human serum albu$\min (\mathrm{HSA})$

\section{Introduction}

As bioclinical applications that use nanoparticles (NPs), such as contrast media and nanomedicine, have increased rapidly, the influence of NPs on living organisms has recently become an important subject, particularly the safety concerns related to their use.

When NPs are exposed in biological media, such as blood, surfaces of NPs are rapidly coated with biomolecules, such as blood proteins. This coating is often referred to as the protein coronas of NPs. ${ }^{1-5}$ In fact, what the cells actually see at the initial stage of interactions of NPs with living organisms is protein coronas rather than the bare surface of NPs. ${ }^{4}$ Thus, it has been suggested that protein coronas presumably play a crucial role in determining the fates of NPs that result in the biological influence of NPs. In particular, in the field of drug delivery research, protein coronas have drawn attention as long as they have been known as they might relate to biodistribution and compatibility and, thus, therapeutic efficacy. ${ }^{5}$ In this regard, extensive research has been performed in recent years to understand the composition ${ }^{5-8}$ and time evolution $^{9-11}$ of the protein coronas of NPs as well as their effects on cellular uptake ${ }^{12-14}$ and blood-brain barrier crossing. ${ }^{15-17}$

The chemical composition of protein coronas may be influenced by the physicochemical properties of NP surfaces. Gel electrophoresis and mass spectrometry have provided primary tools to analyze the compositions of protein coronas that are produced on various NPs. ${ }^{5-8}$ As for the protein coronas of NPs formed in blood plasmas, human serum

${ }^{\mathrm{a}}$ Present address: Research Center for Functional Cellulomics, Institute of Molecular Biology and Genetics, Seoul National University, Seoul 151-747, Korea albumin (HSA) and apolipoproteins have been found to be most pronounced in the coronas, and these were later found
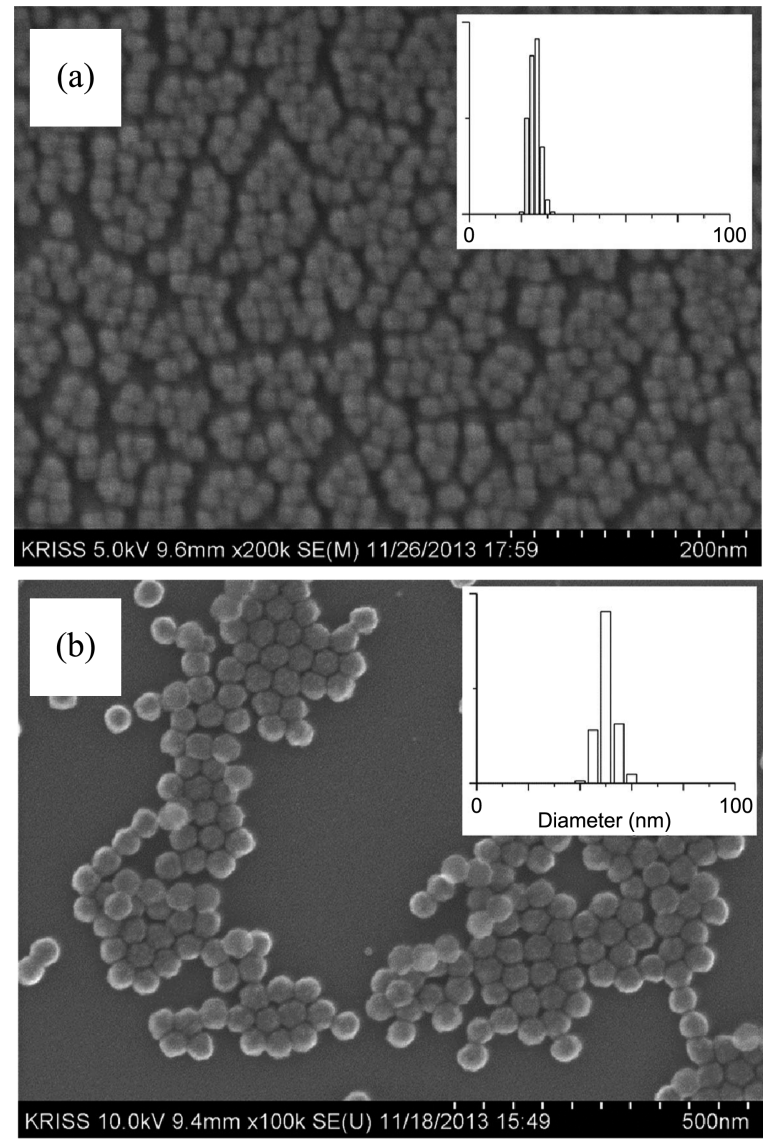

Figure 1. Scanning electron microscopy (SEM) images of silica NPs with (a) a $20 \mathrm{~nm}$ and (b) a $50 \mathrm{~nm}$ diameter. The insets display the respective size distributions measured by SEM. 
to assist cellular intake and the blood-brain barrier crossing of NPs. ${ }^{15-17}$

Optical microscopic techniques, such as fluorescence correlation spectroscopy, have also been applied to investigate the structure and dynamics of corona proteins. In studies that have modeled spectroscopic data, the presence of hard and soft coronas was suggested. ${ }^{9-11}$ Hard coronas that may form a first monolayer appear to be strongly bound and irreversible, while the secondary layer, which is often referred to as soft coronas, has been found to exhibit dynamic exchange of proteins. ${ }^{10}$ Conformational changes of the adsorbing proteins can also occur depending on the particles' curvature and protein stabilities. ${ }^{18,19}$

Silica NPs are widely used in nanochemistry, and the particles' physicochemical properties are well-known. In addition, silica surfaces represent the surfaces of various NPs that are used for bionano applications, as the tetraethyl orthosilicate (TEOS) coating is popularly employed to make insoluble NPs water-soluble. The controlled preparation of silica NPs is also possible, and, thus, silica NPs offer good model systems of well-characterized NPs with narrow size distributions.

Despite extensive research efforts, including method development, to understand the protein coronas of NPs, the understanding of this subject is still limited due to the complex nature of the interactions between NPs and biological systems. In order to address such a complex problem, an approach from a chemists' view may be of value, such as an investigation of the protein adsorption to NPs at the molecular level. In this study, we quantitatively analyzed HSA coronas that formed on well-characterized silica NPs with conventional sodium dodecyl sulfate-polyacrylamide gel electrophoresis (SDS-PAGE) along with the optimized analysis method, where a NP size dependence on HSA adsorption was observed.

\section{Experimental}

Synthesis of Silica NPs. Silica NPs were prepared by the hydrothermal method. In the preparation, TEOS (98\%; ACROS, Thermo Fisher Scientific, Geel, Belgium) was used as a precursor for silica NPs, L-arginine (Sigma-Aldrich Co. LLC, St. Louis, MO, USA) was used as a catalyst, and cyclohexane (99\%; Samchun Chemical Co., Ltd., Seoul, Korea) and deionized water (Millipore-Q water, $18.2 \mathrm{M} \Omega \cdot \mathrm{cm}$ ) were used as reagents without further purification.

For the synthesis of silica NPs with a $20 \mathrm{~nm}$ diameter, the mixture of reagents was allowed to polymerize by stirheating at $50{ }^{\circ} \mathrm{C}$ for $24 \mathrm{~h}$. Silica NPs with a $50 \mathrm{~nm}$ diameter were prepared from silica NPs with a $30 \mathrm{~nm}$ diameter as a seed and by adding TEOS three times $(3.3 \mathrm{~mL}, 5 \mathrm{~mL}$, and 5 $\mathrm{mL}$ every $24 \mathrm{~h}$ ) during the growth reaction at $70{ }^{\circ} \mathrm{C}$ for $72 \mathrm{~h}$. The prepared silica NPs were carefully characterized by ultraviolet-visible spectrophotometry, dynamic light scattering (DLS), and scanning electron microscopy (SEM). For the prepared NPs with a nominal diameter of $20 \mathrm{~nm}$, DLS at $2.6 \mathrm{mg} / \mathrm{mL}$ and SEM gave measured diameters of $19.2 \mathrm{~nm}$ and $23.06 \pm 0.68 \mathrm{~nm}$, respectively. For NPs with a $50 \mathrm{~nm}$ diameter, DLS at $3.3 \mathrm{mg} / \mathrm{mL}$ and SEM gave diameters of $49.8 \mathrm{~nm}$ and $49.04 \pm 1.79 \mathrm{~nm}$, respectively. As shown in Figure 1, the prepared silica NPs displayed narrow size distributions, and this was suitable for studying the size dependence of protein corona formation.

Quantification of HSA Corona with Gel Electrophoresis. The experimental protocol that was utilized in this study for the quantification of protein coronas is outlined in Figure 2. Each step of the protocol was carefully optimized and examined to confirm the reproducibility that is required for quantification.

Silica NPs of $20 \mathrm{~nm}$ and $50 \mathrm{~nm}$ diameters were incubated in HSA solutions (molecular weight $=66.5 \mathrm{kDa}$; A9511; Sigma-Aldrich Co. LLC) covering a broad range of concentrations $(30 \mathrm{ng} / \mu \mathrm{L}, 110 \mathrm{ng} / \mu \mathrm{L}, 220 \mathrm{ng} / \mu \mathrm{L}, 440 \mathrm{ng} / \mu \mathrm{L}, 890 \mathrm{ng} / \mu \mathrm{L}$, $1.8 \mu \mathrm{g} / \mu \mathrm{L}, 3.6 \mu \mathrm{g} / \mu \mathrm{L}, 5.6 \mu \mathrm{g} / \mu \mathrm{L}, 11.1 \mu \mathrm{g} / \mu \mathrm{L}, 16.7 \mu \mathrm{g} / \mu \mathrm{L}$, and $22.2 \mu \mathrm{g} / \mu \mathrm{L})$ at $25^{\circ} \mathrm{C}$ for $1 \mathrm{~h}$. The incubation was performed in a buffer solution that included $10 \mathrm{mM}$ Tris- $\mathrm{Cl}$ and $150 \mathrm{mM}$ $\mathrm{NaCl}$ (pH 7.5).

After incubation, a washing process to remove unbound free proteins from the solution was conducted by repeating the centrifugation and resuspension of protein-coated silica NPs three times. The incubated mixture possessing proteincoated silica NPs and unbound proteins was subject to centrifugation at $16,870 \times \mathrm{g}$ for $30 \mathrm{~min}$. With this centrifugation condition, the precipitation of free proteins was rarely observed. The supernatant was removed with a micropipette

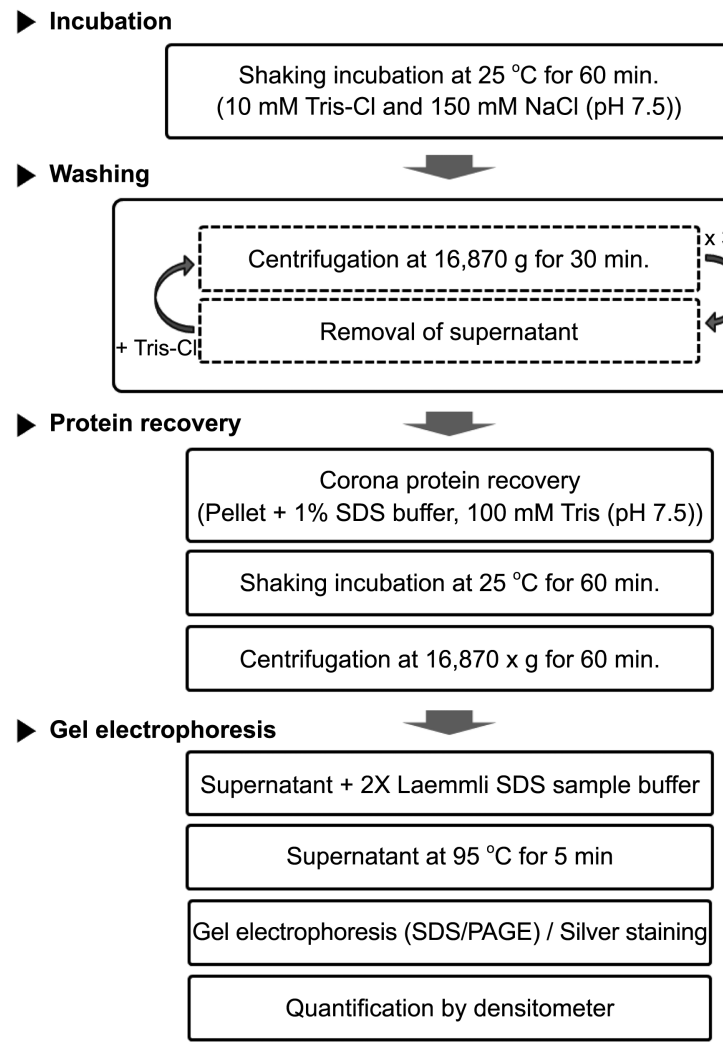

Figure 2. Experimental procedure for the quantification of protein coronas with sodium dodecyl sulfate-polyacrylamide gel electrophoresis (SDS-PAGE). 
and stored separately in a $1.5-\mathrm{mL}$ centrifuge tube at $4{ }^{\circ} \mathrm{C}$. The pellet, including the protein-coated silica NPs, was then resuspended with the same buffer solution that was used in the incubation step. Washing was performed by repeating the above steps three times. Separate analysis of the supernatant with SDS-PAGE gel electrophoresis showed that three washes effectively removed most of the free proteins from the solution.

The washed pellet was treated with the SDS-containing buffer solution (100 mM Tris; $\mathrm{pH}$ 7.5). Adsorbed proteins were released with the surfactant (SDS) into the solution during the shaking incubation that was performed at $25{ }^{\circ} \mathrm{C}$ for $60 \mathrm{~min}$. The solution was subjected to centrifugation for $60 \mathrm{~min}$. The supernatant was taken and mixed with the Laemmli SDS sample buffer $(2 \times$, nonreducing). The solution was heated for $5 \mathrm{~min}$ at $95{ }^{\circ} \mathrm{C}$ to denature the proteins before the SDS-PAGE.

Conventional SDS-PAGE was performed, and it typically took $45 \mathrm{~min}$ at $180 \mathrm{~V}$. In the gel, a known amount of HSA molecules was also loaded, and it provided a quantity reference (R) to quantify the HSA that was adsorbed on silica NPs by comparison. After a gel electrophoresis run, the gel was silver-stained. When the development for the silverstaining was completed, the gel was stored in $1 \%$ acetic acid until analysis. Quantification of the bands that appeared in the gel was conducted with a densitometer (GS-800, BioRad Laboratories, Inc., Hercules, CA, USA) and an imaging program (Quantity-1, Bio-Rad Laboratories, Inc.) (Figure 3). The linear response of the SDS-PAGE was carefully examined by obtaining a linear calibration curve using a set of known concentrations of HSA covering the present experimental range. To avoid possible saturation of the densitometer, the loading amounts of samples were controlled to be in the linear response range of the densitometer as well.

\section{Results and Discussion}

As shown in Figure 3, the experiments on protein corona formation (i.e., HSA adsorption) were conducted with a wide range of HSA incubation concentrations $(0.03 \mu \mathrm{g} / \mu \mathrm{L}$ $25 \mu \mathrm{g} / \mu \mathrm{L})$. Using the protocol described in the experimental section, the amounts of HSA molecules in the protein coronas were quantified by gel electrophoresis (SDS-PAGE), in which free HSA of a known amount provided the internal reference (R) for quantification. Although the isolated protein (HSA) was employed in this study, unavoidable protein fragmentations occurred during the experiments, and this gave a series of bands in a lane. However, the fragmentation patterns were reproducible in terms of the ratio between the fragments and the main HSA band $(66.5 \mathrm{kDa})$ so that the main protein bands were taken for the analysis.

In Figure 3(c), the quantities of the adsorbed proteins (i.e., the HSA corona) are plotted as a function of the HSA concentration used in the incubation. The plots show that, as the HSA concentration increases, the adsorbed protein amount also increases until saturation of the adsorption occurs. Saturation occurs earlier at a concentration less than

(a)

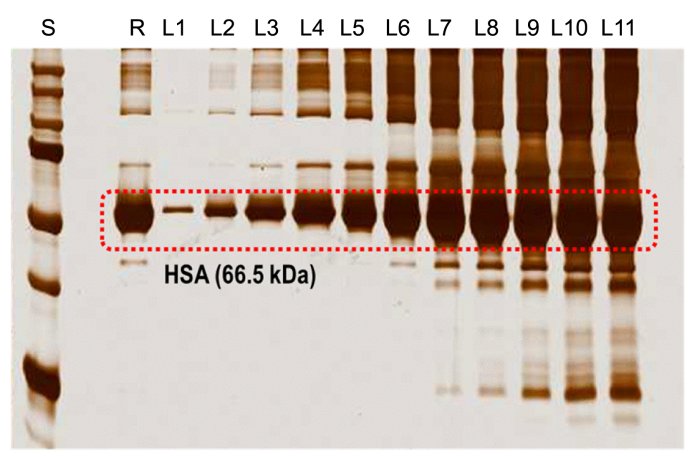

(b)

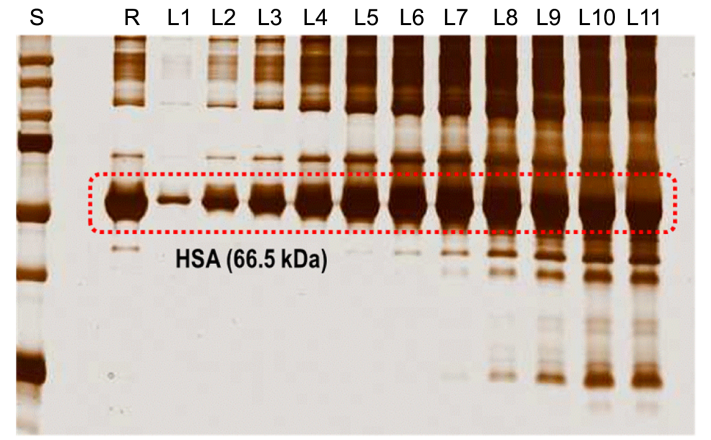

(c)

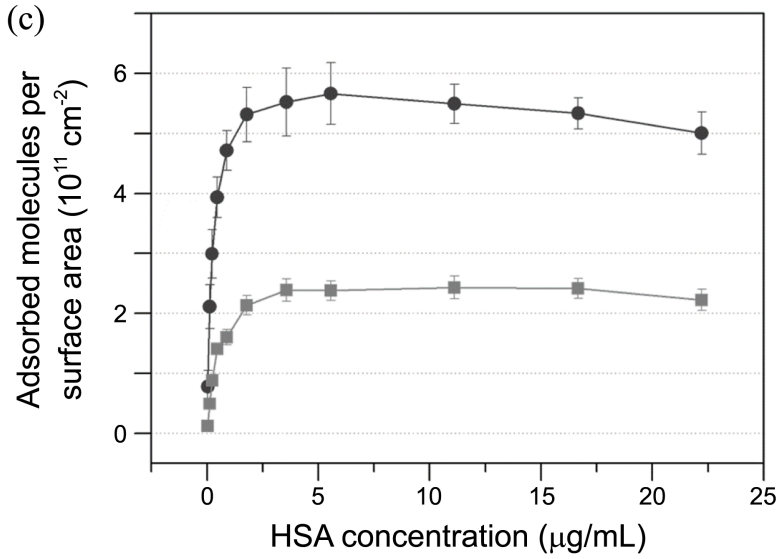

Figure 3. Gel electrophoresis (SDS-PAGE) of human serum albumin (HSA) coronas obtained from the surfaces of silica NPs with (a) a $20 \mathrm{~nm}$ and (b) $50 \mathrm{~nm}$ diameter, respectively. The (S) and (R) lanes show the size markers and an internal reference of a known amount of HSA molecules, respectively. The L1 to L11 lanes differ in the HSA concentrations employed in the incubation: $\mathrm{L} 1$ to $\mathrm{L} 11$ correspond to $30 \mathrm{ng} / \mu \mathrm{L}, 110 \mathrm{ng} / \mu \mathrm{L}, 220 \mathrm{ng} / \mu \mathrm{L}, 440 \mathrm{ng} /$ $\mu \mathrm{L}, 890 \mathrm{ng} / \mu \mathrm{L}, 1.8 \mu \mathrm{g} / \mu \mathrm{L}, 3.6 \mu \mathrm{g} / \mu \mathrm{L}, 5.6 \mu \mathrm{g} / \mu \mathrm{L}, 11.1 \mu \mathrm{g} / \mu \mathrm{L}, 16.7$ $\mu \mathrm{g} / \mu \mathrm{L}$, and $22.2 \mu \mathrm{g} / \mu \mathrm{L}$ of HSA, respectively. (c) Plots of the evaluated numbers of adsorbed HSA molecules per NP surface area for silica NPs with a $20 \mathrm{~nm}(\boldsymbol{\square})$ and $50 \mathrm{~nm}(\bullet)$ diameter. The error bars indicate the standard deviations obtained from 4 independent measurements.

$2.5 \mu \mathrm{g} / \mu \mathrm{L}$. After saturation, the amount of HSA in the protein corona remained essentially the same. As the experiment was carried out in the range of linear response of the densitometer, the observed saturations were not instrumental artifacts at all. These findings suggested that a certain stable shell of adsorbed proteins was established. In addition, considering that the typical concentration of albumin in the 
serum is about $35-50 \mu \mathrm{g} / \mu \mathrm{L}$, the surfaces of the silica NPs would be fully coated with serum albumin when exposed in blood. It was also observed that the adsorption equilibrium was completed rather rapidly on a time scale less than minutes.

The adsorbed quantities at saturation can be used to estimate the maximum number of adsorbed molecules per silica NP. With a concentration of silica NPs of $10 \mu \mathrm{g} / \mathrm{mL}$ and a literature density of silica of $2.65 \mathrm{~g} / \mathrm{cm}^{3}$, the average numbers of HSA adsorbed on the silica NPs of a $20 \mathrm{~nm}$ and $50 \mathrm{~nm}$ diameter were calculated to be about 3 and 43 molecules, respectively. A rough estimate for the area of a single HSA molecule from crystallographic data (a dimension of $8 \mathrm{~nm} \times 4 \mathrm{~nm}$ ) was about $2 \times 10^{-12} \mathrm{~cm}^{-2}$. Considering that the surface areas for spheres with a $20 \mathrm{~nm}$ and $50 \mathrm{~nm}$ diameter were $12.6 \times 10^{-12} \mathrm{~cm}^{2}$ and $78.5 \times 10^{-12} \mathrm{~cm}^{2}$, respectively $\left(\mathrm{V}=4 \pi \mathrm{r}^{3}\right)$, this yielded an estimate for the theoretical numbers of HSA molecules in a single adsorbed layer to be 6.5 and 39 molecules per NP with a $20 \mathrm{~nm}$ and $50 \mathrm{~nm}$ diameter, respectively. Compared to the electrophoresis results of 3 and 43 HSAs on silica NPs with a $20 \mathrm{~nm}$ and $50 \mathrm{~nm}$ diameter, respectively, these findings indicated that adsorbed proteins most likely form a monolayer on silica NPs, which was in good accordance with previous observations that used optical methods, which supported the formation of "hard protein coronas" on silica NP surfaces. As found in this study, the hard protein coronas are indeed stable, which survived through three times of washing steps. However, the soft coronas, the secondary layer of protein adsorption, might be washed away during the washing process. ${ }^{10}$

The features of HSA corona formation become more interesting when they are considered in terms of the numbers of adsorbed molecules in a unit area. As shown in Figure 3(c), the maximum number of adsorbed molecules per area displays a clear size dependence, in which smaller silica NPs of a $20 \mathrm{~nm}$ diameter cannot accommodate HSA molecules in full coverage for a monolayer, while NPs of a $50 \mathrm{~nm}$ diameter can. As the surface chemical properties of the two silica NPs might not be very different, the effects of different surface curvatures might play an important role in the observed size dependence. As the primary nature of the interaction between HSA molecules and silica NPs might be electrostatic, the curvature may exert an effect on adsorption in this size range as is coincidently reflected in different $\zeta$ potentials for the two silica NPs, $-61.95 \mathrm{mV}$ and $-24.06 \mathrm{mV}$ for the $20 \mathrm{~nm}$ and $50 \mathrm{~nm}$ silica NPs, respectively.

\section{Conclusion}

In order to examine the formation of protein coronas at the molecular level, HSA adsorption on $20 \mathrm{~nm}$ and $50 \mathrm{~nm}$ silica NPs was investigated with gel electrophoresis. The results showed that the adsorption of HSA to silica NPs preferentially formed a monolayer, which appeared to be strongly bound as it survived through the washing procedure. Interest- ingly, protein adsorption was found to be NP size-dependent, and it became less favorable to NP surfaces with a higher curvature. This study showed the presence of a strongly bound monolayer in a protein corona, and this was in good agreement with the concept of a hard corona that has been previously suggested in optical measurements. Thereby, the present approach provided a good model system for further study of the stability and protein exchange of the protein corona in a quantitative way.

Acknowledgments. This work was supported by the research program of Gachon University (GCU-2014-0120). SY thanks to Dr. Nam Woong Song (KRISS) for synthesis and characterization of silica NPs and valuable comments.

\section{References}

1. Monopoli, M. P.; Aberg, C.; Salvati, A.; Dawson, K. A. Nat. Nanotech. 2012, 7, 779 .

2. Cedervall, T.; Lynch, I.; Lindman, S.; Berggård, T.; Thulin, E.; Nilsson, H.; Dawson, K. A.; Linse, S. Proc. Natl. Acad. Soc. USA 2007, 104, 2050.

3. Lundqvist, M.; Stigler, J.; Elia, G.; Lynch, I.; Cedervall, T.; Dawson, K. A. Proc. Natl. Acad. Soc. USA 2008, 105, 14265.

4. Walczyk, D.; Bombelli, F. B.; Monopoli, M. P.; Lynch, I.; Dawson, K. A. J. Am. Chem. Soc. 2010, 132, 5761.

5. Aggarwal, P.; Hall, J. B.; McLeland, C. B.; Dobrovolskaia, M. A.; McNeil, S. E. Adv. Drug Deliv. Rev. 2009, 61, 428

6. Tenzer, S.; Docter, D.; Rosfa, S.; Wlodarski, A.; Kuharev, J.; Rekik, A.; Knauer, S. K.; Bantz, C.; Nawroth, T.; Bier, C.; Sirirattanapan, J.; Mann, W.; Treuel, L.; Zellner, R.; Maskos, M; Schild, H.; Stauber, R. H. ACS Nano 2011, 5, 7155.

7. Cedervall, T.; Lynch, I.; Foy, M.; Berggård, T.; Donnelly, S. C.; Cagney, G.; Linse, S.; Dawson, K. A. Angew. Chem. Int. Ed. 2007, 46, 5754 .

8. Ruh, H.; Kühl, B.; Brenner-Weiss, G.; Hopf, C.; Diabate, S.; Weiss, C. Toxicol. Lett. 2012, 208, 41.

9. Rocker, C.; Pötzl, M.; Zhang, F.; Parak, W. J.; Nienhaus, G. U. Nat. Nanotech. 2009, 4, 577.

10. Milani, S.; Bombelli, F. B.; Pitek, A. S.; Dawson, K. A.; Rädler, J. ACS Nano 2012, 6, 2532.

11. Casals, E.; Pfaller, T.; Duschl, A.; Oostingh, G. J.; Puntes, V. ACS Nano 2010, 4, 3623.

12. Lesniak, A.; Fenaroli, F.; Monopoli, M. P.; Åberg, C.; Dawson, K. A.; Salvati, A. ACS Nano 2012, 6, 5845.

13. Sund, J.; Alenius, H.; Vippola, M.; Savolainen, K.; Puustinen, A.; ACS Nano 2011, 5, 4300.

14. Shapero, K.; Fenaroli, F.; Lynch, I.; Cottell, D. C.; Salvati, A.; Dawson, K. A. Mol. Biosyst. 2011, 7, 371.

15. Kratzer, I.; Wernig, K.; Panzenboeck, U.; Bernhart, E.; Reicher, H.; Wronski, R.; Windisch, M.; Hammer, A.; Malle, E.; Zimmer, A.; Sattler, W. J. Control. Release 2007, 117, 301.

16. Michaelis, K.; Hoffmann, M. M.; Dreis, S.; Herbert, E.; Alyautidin, R. N.; Michaelis, M.; Kreuter, J.; Langer, K. J. Pharmacol. Exp. Ther. 2006, 317, 1246.

17. Kreuter, J.; Hekmatara, T.; Dreis, S.; Vogel, T.; Gelperina, S.; Langer, K. J. Control. Release 2007, 118, 54.

18. Lundqvist, M.; Sethson, I.; Jonsson, B.-H. Langmuir 2004, 20, 10639 .

19. Shrivastava, S.; Nuffer, J. H.; Siegel, R. W.; Dordick, J. S. Nano Lett. 2012, 12, 1583. 